
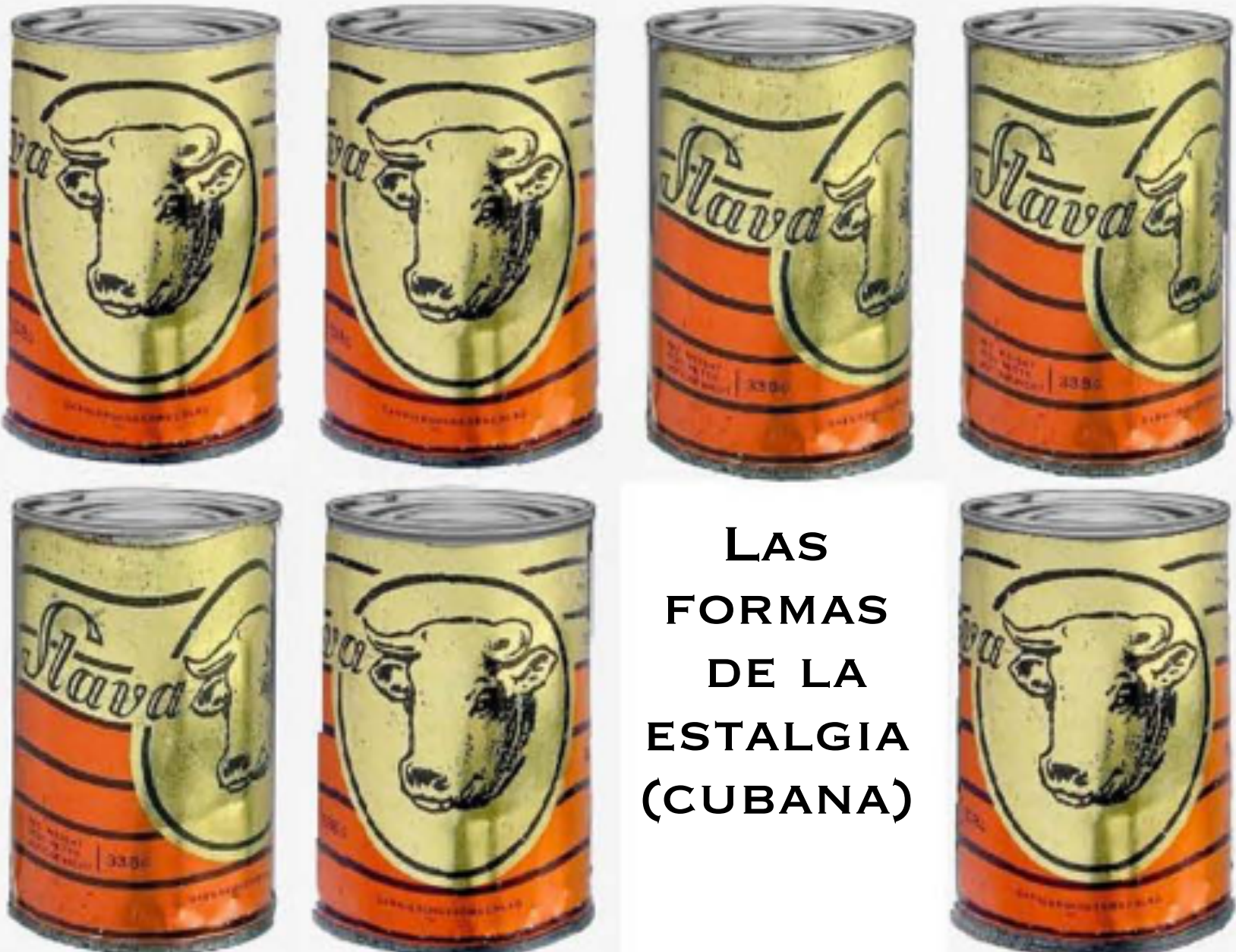

ESTALGIA
(CUBANA)
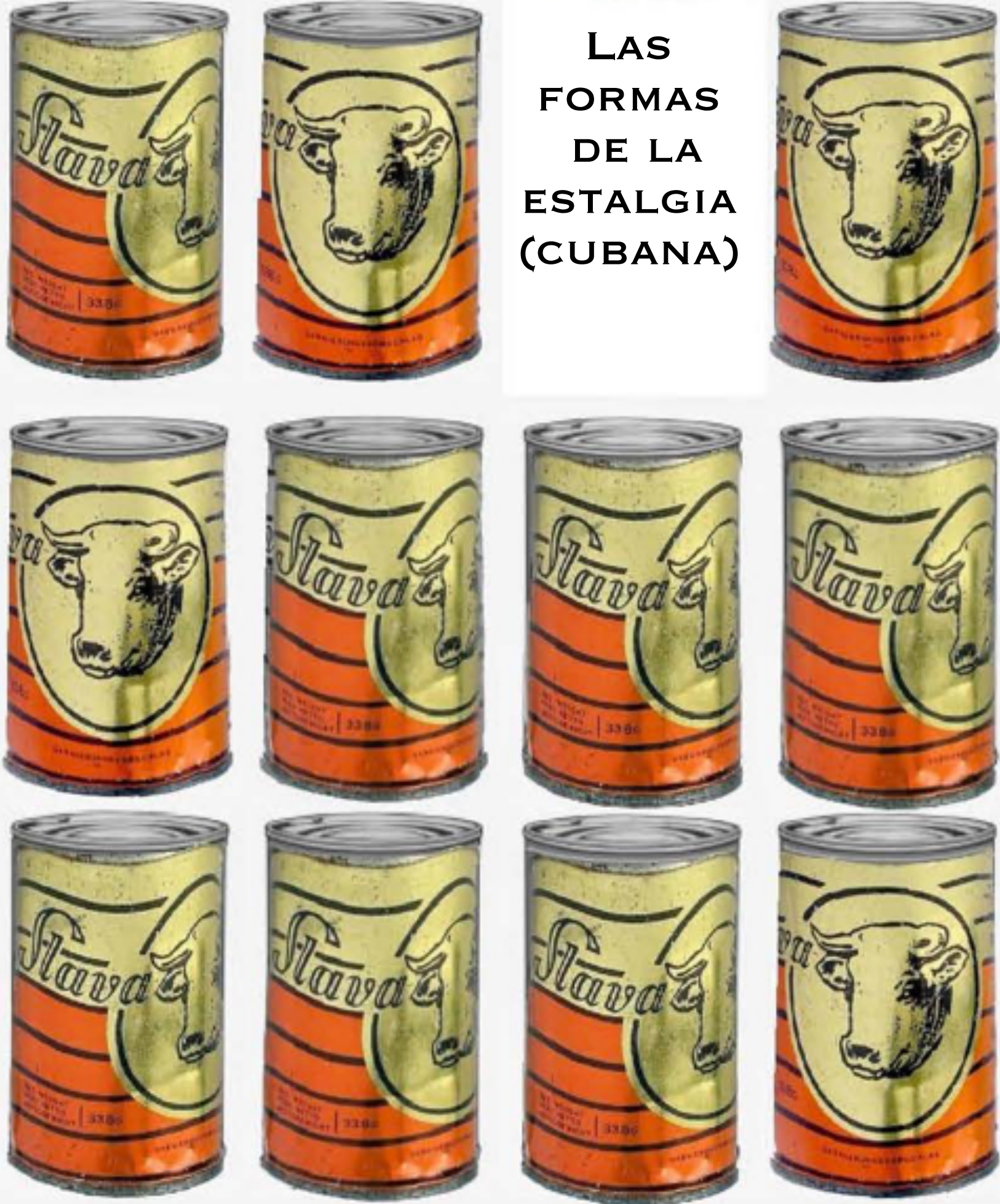

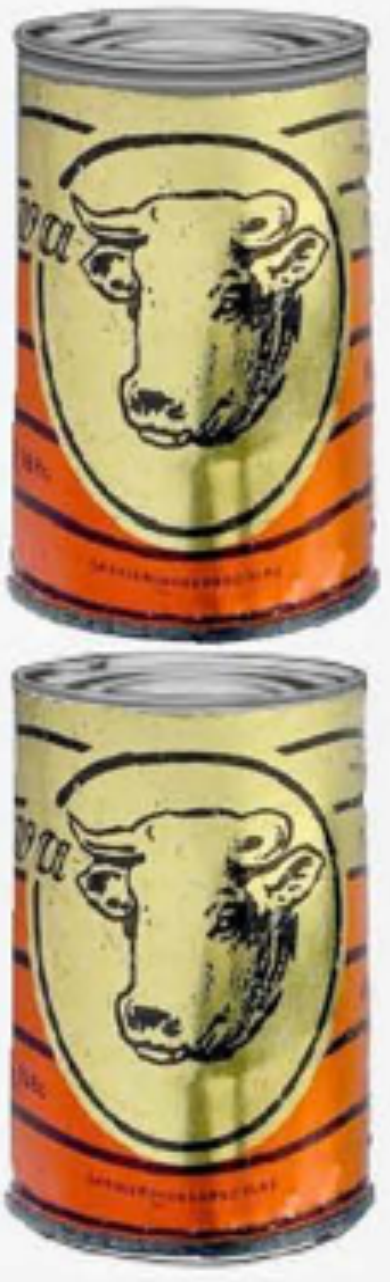




\title{
Las formas de la estalgia (cubana)
}

\author{
Forms of (Cuban) Eastalgia
}

Monográfico coordinado por

Carlos Muguiro Altuna

Universidad de Navarra • cmugiro@unav.es

Profesor de Estética y de Comisariado y programación cinematográfica en la Universidad de Navarra. Director de la especialidad de cine documental de la Escuela de Cine de Madrid. Doctor en Humanidades en el Departamento de Estudios Eslavos de la Universidad Pompeu Fabra, donde ha desarrollado su actividad investigadora en torno a la representación de la naturaleza y el paisaje en cine ruso-soviético. Ha publicado, entre otros libros, Ver sin Vértov. Cincuenta años de cine de no-ficción en Rusia y la URSS y co-editado Alan Berliner. The Man Without the Movie Camara.

Imagen de portada: Camilo Villalvilla.

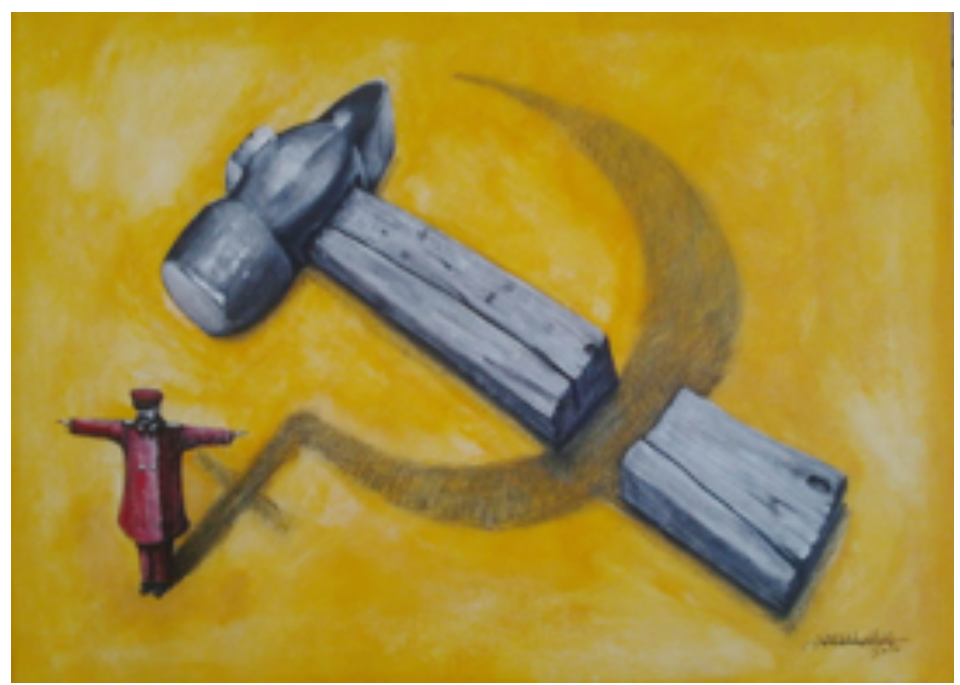

Hoz, martillo, sombra. Camilo Villalvilla

(Carboncillo y acrilico sobre lienzo. 40 x $67 \mathrm{~cm}$ )

DOI: 10.7203/KAM.5.6800 
Este monográfico de Kamchatka titulado Las formas de la estalgia está dedicado a analizar las huellas, evocaciones y presencias, reales e imaginadas, de lo ruso-soviético en Cuba desde 1961 a la actualidad. Las primeras, las trazas reales, se deben a la cotidianidad de lo ruso-soviético en la vida de los cubanos durante treinta años, hasta 1991. Desde que Fidel Castro definió la naturaleza comunista de la revolución de 1959, la URSS y Cuba abrieron un periodo de intercambio económico y cultural muy estrecho, aunque ciertamente desigual, con clara predominancia soviética, que afectó a todos los órdenes de la vida, de la alta política al menú diario. Cuba conoció en aquellos treinta años el exceso de la siempre excesiva Rusia (y de la URSS).

Las segundas, las trazas imaginarias, las construcciones de la memoria, huellas menos evidentes que las anteriores y con frecuencia incompartibles más allá de la comunidad emocional que vivió este periodo, comenzaron a manifestarse con la abrupta desaparición de la URSS en 1991. El colapso del bloque soviético provocó, además de la gran crisis de desabastecimiento llamada Periodo Especial, un vaciamiento de lo ruso tan elocuente como el exceso previo. Ciertamente, en la isla quedaron todos los objetos de memoria (los coches Moskviches, Nivas o Ladas, las lavadoras Aurika, los libros de Progreso o Raduga, los televisores Electkron, los ventiladores Orbita, las películas ambientadas en la Gran Guerra Patriótica) y el gran depósito de recuerdos de quienes habían crecido bajo la evocación del Lejano Este. Ahora bien, aquellos recuerdos del pasado, recuerdos detenidos en 1991, adquirieron a lo largo de la década siguiente no sólo la pátina natural del tiempo, sino un estigma entrópico que los hacían aparecer como restos de una utopía perdida, como ruinas del futuro, vestigios de un pasado en el que el futuro era una obligación. Como nos recuerda Svetlana Boym, la nostalgia contemporánea, particularmente en los países que compartieron en algún momento el proyecto soviético (la llamada ostalgia o estalgia), parece afectada por cierta tristeza utópica, no por la añoranza de un régimen político, sino porque busca "obliterar la historia y transformarla en cierta clase de mitología privada o colectiva, porque quiere revistar el tiempo como si fuera espacio" (2001: XV).

En Cuba, a partir del año 2000, curadas en parte las heridas de la orfandad rusa, artistas, músicos y escritores cubanos comenzaron a revisar la historia reciente de las relaciones con la URSS y a través del arte se comenzó a desentrañar qué significaba lo ruso para toda su generación. La comunidad crecida en esta presencia/ausencia comenzó a reconocerse como un sujeto emocional, como una comunidad unida por una serie de recuerdos, de valores y de imágenes. Entre esos valores estaba también el sentimiento de pérdida y añoranza, no siempre positivo, ni mucho menos. En la interpretación más pegada a la etimología, nostalgia es el estado de profunda tristeza originado al estar lejos de la tierra natal. Pero, ¿cómo deberíamos llamar a ese mismo dolor de ausencia cuando la que se aleja es la tierra misma; es 
decir, cuando es el paisaje (emocional, familiar, cotidiano, físico) el que vemos alejarse y lo que queda es el vacío, no necesariamente feliz ni complaciente, dejado por aquel decorado?

Si tomáramos como pauta metodológica las categorías desarrolladas por Svetlana Boym, la nostalgia del Este en Cuba se manifiesta fundamentalmente en dos comunidades emocionales. La primera corresponde a la llamada primera generación de parejas mixtas cubano-soviéticas, a sus hijos y también a sus nietos, ya en algunos casos. En el habla popular cubana hay muchos términos para referirse a este grupo humano: los mitad-y-mitad, los aguatibias, los poloviny, los ruso-cubanos, los sovkubintsi, los ucraniano-cubanos, los kazajo-cubanos, los georgiano-cubanos, los bieloruso-cubanos... Portadores de una identidad turbia. Para todos ellos la nostalgia tiene un referente real, incluso espacial, localizado en el pasado. En su nostalgia predomina el nostos (del griego vóotos, regreso), un suelo físico al que siempre se ansía volver (cuando están en Cuba, ese destino es Rusia; cuando están en Rusia, Cuba), pero al que nunca es posible regresar del todo (falta Cuba cuando se está en Rusia, falta Rusia cuando se está en la isla). Este sentimiento coincide con la nostalgia restaurativa de Svetlana Boym, porque en su interior se activa la necesidad de completar los vacíos de la memoria, a veces incluso actualizando el pasado de una manera anacrónica (2001: 41 y ss.).

La segunda forma de estalgia afecta a aquellos cubanos que, aun no teniendo sangre eslava, sin embargo, vuelcan sobre el recuerdo de lo soviético un indeterminado, problemático y nada dulce anhelo

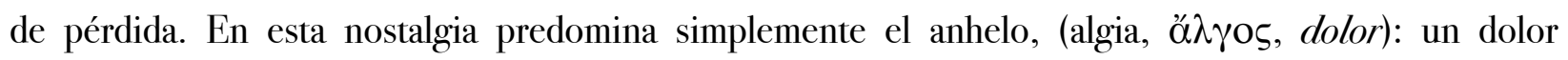
intransitivo que no tiene un objeto de deseo, sino que se vuelca sobre el sentimiento mismo de añorar. Como explica Kundera, "en español, añoranza proviene del verbo añorar, que proviene a su vez del catalán enyorar, derivado del verbo latino ignorare, (ignorar, no saber algo). A la luz de esta etimología, la nostalgia se nos revela como el dolor de la ignorancia. Estás lejos, y no sé que ha sido de ti” (2000: 5-6). En la categorización de Boym, esta añoranza se correspondería con la nostalgia reflexiva, definida por el imaginario emocional que unifica y cohesiona a una colectividad, y que con frecuencia sólo pueden reconocer quienes forman parte del grupo. En cierta medida, la dimensión emocional y reflexiva de esta nostalgia correspondería a lo que Lev Vygotsky ha llamado también mediación cultural. "Décadas de influencia soviética -concluye Damaris Puñales-Alpízar- moldearon una nueva identidad: inestable, multilingüe, dispersa y en transición" (2012: 33)

Las herramientas teóricas que proporciona Svetlana Boym resultan muy útiles para enmarcar nuestro objeto de estudio desde la estética de la nostalgia. Sin embargo, la hibridación cubano-soviética es un asunto complejo, a veces nada complaciente e incluso contradictorio (como siempre lo ha sido el mismo concepto de nostalgia). Requiere acercamientos desde otros ámbitos académicos, como los estudios de memoria, el análisis histórico post-colonial, los conceptos de hibridación cultural aplicados a 
Latinoamérica o las recientes miradas interdisciplinares sobre la construcción de la cultura emocional. Además, dado que la actualidad del fenómeno es coetánea a su estudio, este abordaje intelectual pide la incorporación al debate de otros aportes no académicos, documentos biográficos, testimonios artísticos, audiovisuales, musicales y literarios. La suma de todas estas contribuciones ayuda a entender mejor la extraordinaria riqueza del que es uno de los cruces culturales más desconcertantes del siglo XX. Desde el punto de vista intelectual y académico, el primer gran esfuerzo sistematizador de la "nostalgia al estilo cubano" debemos fijarlo en el simposio Cuba-URSS y la experiencia post-soviética que, convocado por Jacqueline Loss y José Manuel Prieto, se celebró en 2007 en la Universidad de Connecticut. Aquel evento no creó el sentimiento, pero sí lo hizo visible, observable y analizable como un objeto coherente y unitario. Las aportaciones del simposio aparecieron después reflejadas en el volumen Caviar with Rum, sin duda una obra fundacional, cuyo espíritu pionero ha seguido ampliando la propia Jacqueline Loss en otros trabajos monográficos como Dreaming in Russian. Este monográfico de Kamchatka, Las formas de la estalgia, aspira a incorporarse a la joven tradición académica que inauguró aquel evento; tradición que después ha sido ampliada por otros estudiosos cubanos y estadounidenses, pero que permanece inexplorada en España. Pretende hacerlo con dos obras complementarias pero autónomas. Por un lado, con este monográfico correspondiente al número 5 de la revista, conformado por aportaciones académicas, material documental y textos ensayísticos. Por otro, con un volumen dedicado en exclusiva a la creación literaria, que antologa la obra narrativa y poética reciente de algunos de los autores cubanos post-soviéticos más interesantes. Remito a la introducción de Mi abuelo murió leyendo a Pushkin, título de la antología literaria, para una mayor información sobre el origen y propósito de dicho volumen. En las líneas siguientes me centraré específicamente en la estructura y contenidos del monográfico Las formas de la estalgia.

El grueso de esta publicación lo integran artículos académicos de investigación escritos por algunos de los autores más relevantes en este área a nivel internacional. A su vez, como se ha argumentado previamente, este núcleo de reflexión está arropado con aportaciones de otra naturaleza, más ensayística o de creación, con el fin de expandir la noción de estalgia y estimular nuevos debates. Todos estos contenidos, en su diversidad temática y heterogeneidad estilística, están estructurados en torno a cuatro secciones. La primera, Identificación de la estalgia (cubana), se adentra en la compleja definición de nuestro campo de estudio. De manera plenamente intencionada, por lo dicho en las líneas precedentes, el monográfico arranca con un artículo de Jacqueline Loss y José Manuel Prieto, “Caviar con ron: Sdelano na Kube”, en el que estos dos autores reflexionan sobre las transformaciones que en la última década se han producido sobre la memorialización de lo ruso en Cuba. Desde su experiencia como organizadores del simposio de 2007 al que nos hemos referido, Loss y Prieto relatan las etapas 
principales (“de una negación rotunda a una aceptación actual que no dudarían en llamar entusiasta”, escriben) y el estado actual de la cuestión del imaginario cubano de lo ruso-soviético. De manera más específica, Iván Darias Alfonso centra su artículo, "Muñequitos rusos: la nostalgia y su contexto en la diáspora cubana”, en la importancia que los dibujos animados soviéticos, emitidos durante décadas en la Televisión Cubana, tuvieron en la construcción de una memoria mediática y en la vinculación afectiva transnacional entre los emigrados cubanos que crecieron viendo dichos episodios. A esa generación pertenece Odette Cisneros, que en "How Long is Now?: Extravíos berlineses (1993-2015)” entrelaza lo biográfico y lo ficticio para describir su primer viaje fuera de Cuba a comienzos de los años noventa, viaje que coincide, precisamente, con el fin del bloque soviético y la reunificación alemana. Desde esa encrucijada de la historia, Cisneros reflexiona sobre lo sentimental y lo político, recapitulando aquello que nunca tuvo, como la sociedad prometida en los eslóganes y discursos. La aportación de Verónica Proskurnina en "Moriré en Moscú con aguacero" explora la cuestión de la identidad de quienes, como ella, comparten el doble origen ruso-cubano. Su caso evidencia la complejidad no sólo emocional sino también política del tema al sumar a su relato autobiográfico la dimensión añadida del exilio, personalizada en el caso de su padre, nacido en el Oriente de Cuba, pero muerto en el Este, en Moscú, diez años después de abandonar la isla. "Siempre quiso volver a Cuba (...) y nunca quiso estar enterrado en Rusia, quedar ahí para siempre”, reconoce la autora.

La sección se complementa con dos relatos que ilustran bien la extraña hibridación de lo eslavocubano. En "Esquema de frecuencias" Antonio Armenteros relata el viaje aturdido y delirante al corazón de la Rusia rural post-comunista de un cubano acompañando a su prometida, Olia. Por su parte, Enrique Pineda Barnet insiste en este choque cultural, reconstruyendo en unas pocas líneas los veinte años de relación con la familia de María Ivanna Kozlova, a la que conoció cuando en 1964 se instaló en Moscú para escribir el guión de Soy Cuba (Ia Kuba, Mikhail Kalatózov). Este primer capítulo se cierra con la reedición de un documento aparecido en el número 0 de la revista Dédalo en 2003, prácticamente inencontrable a día de hoy, que pasa por ser la primera muestra del cambio sobre la memorialización de lo soviético que se produce en Cuba tras el Periodo Especial. En su artículo, Víctor Fowler Calzada planteaba abiertamente, en una actitud ciertamente heterodoxa en su momento, que "uno de los errores lamentables de nuestra política cultural reciente ha sido el haberse resignado a la sustracción de la producción cultural de los países del antiguo bloque socialista”.

Slovo-La Palabra, segunda sección del monográfico, abunda en lo verbal, en lo literario, en las dos lenguas (ruso y español), como territorio particularmente sensible a los conflictos, influencias e hibridaciones entre lo cubano y lo soviético. En "De la presencia impuesta a la presente ausencia: traducción de la teoría cultural rusa en Cuba por Desiderio Navarro (1960-2009)”, Raúl Ernesto Colon 
se centra en la evolución personal e intelectual de Desiderio Navarro, el principal intérprete del pensamiento estético ruso-soviético en la isla, fundamentalmente a través de la revista Criterios, incorporando al análisis el contexto y las contradicciones inherentes a los procesos político-sociales de la URSS y Cuba. Vladímir Alexánder Smith-Mesa, por su parte, atendiendo a los rusismos-sovietismos que llegaron a la isla en diferentes épocas, intenta confirmar en "Slovo Cubano: el vocablo soviético en el español de Cuba” que desde 1961 hasta 1991 este país fue el gran transculturador de lo ruso-soviético en el universo de habla hispana, en las Américas y en el llamado Tercer Mundo. Carola Heinrich toma como campo de estudio específicamente el cuento cubano contemporáneo (desde los años noventa), con el fin de desentrañar las huellas soviéticas que pueden rastrearse en esas páginas, a partir de conceptos como 'lo soviético', ‘lo cubano', 'lo ajeno' y 'lo propio'. La sección se cierra con el artículo “Cuba Socialista. De la traducción y sus secuelas", en el que Damaris Puñales-Alpízar se propone dilucidar el papel periférico o central que la literatura soviética tuvo en la conformación del polisistema literario de la isla, no sólo en el impulso de una ideología de estado sino también en la tradición de la traducción en Cuba que, como explica la autora, siempre ha sido una herramienta esencial para la conformación de la idea de nación desde las letras.

Hemos mencionado líneas arriba las conexiones que pueden establecerse entre nostalgia y utopía, aparentemente alejadas por cuanto la primera parece referirse al pasado y la segunda a futuro. El asunto resulta, sin embargo, de una gran complejidad, como lo ejemplifica el tercero de los epígrafes de este monográfico, El Futuro, que pone el foco específicamente en las confluencias entre la ciencia-ficción soviética y la cubana. Revisitar desde el presente cómo la SF soviética y cubana imaginaron el futuro activa un verdadero caleidoscopio de evocaciones nostálgicas que cuestionan cualquier interpretación ortodoxa de la nostalgia como mera añoranza del pasado. Al regresar sobre la ciencia-ficción, la nostalgia no evoca un pasado pretérito, sino el futuro del pasado, de tal manera que este anhelo se configura entonces, en términos de Boym, como verdadera nostalgia del futuro. En este punto coinciden los tres autores convocados en este apartado. Juan Carlos Toledano aborda en "Sputniks cubanos" cómo la literatura de CF cubana estuvo marcada por la estrecha relación entre el mundo editorial de la URSS y la Cuba castrista de los setenta y ochenta. En los textos siguientes, el análisis queda en manos de dos de los principales escritores cubanos del género. En “¡El futuro pertenece por entero al comunismo!”, Raúl Aguiar propone revisar las conexiones entre el cine de ciencia-ficción ruso-soviético estrenado en Cuba, bien en salas, bien en televisión, y la construcción de un cierto imaginario en la literatura isleña. José Miguel Sánchez Gómez, Yoss, toma el relevo desde la caída del Muro de Berlín para detenerse con más detalle en los ecos del género en la literatura cubana contemporánea, tal y como se deduce del título de su artículo, "Lo que quedó de Cuba cuando los rusos se fueron a la órbita”. 
Arsenal de la estalgia, cuarta sección del monográfico, quiere ser un gran almacén de la memoria material y emocional, a partir de la cual es posible plantear vuelos distintos sobre la construcción de la nostalgia: depósito de objetos, modas, películas, paisajes e imágenes que funcionan como repositorios de tiempo. El primer artículo, "Pañoletas y polainas", de María Antonia Cabrera, explora el rol de las dinámicas de la moda en la consolidación del socialismo de estado de tipo soviético en Cuba en los años sesenta y setenta. El régimen cubano, argumenta la autora, conectó los estilos de la moda con la argumentación política, generando así valores denotativos de la cultura material que hoy aparecen con nitidez. "Kinofikatsia cubana y sus fantasmas", artículo firmado por mí, se adentra en los archivos rusosoviéticos de la Cinemateca de Cuba para hacer un inventario de la presencia y ausencia del cine soviético en las pantallas de la isla entre 1961 y 1991. Entre los contenidos de esta cuarta sección se incluye también el cortometraje Todo tiempo pasado, de Zoe García, producido en 2008. El filme toma la destrucción del restaurante Moscú a causa de un incendio como elemento catalizador para un ejercicio de memoria en el que se ven involucrados distintas generaciones de cubanos. Las ruinas de otro paisaje, la Ciudad Electro Nuclear de Juraguá, en Cienfuegos, aparece en la película La obra del siglo como palimpsesto en el que se superponen distintos estratos del pasado vivido y del pasado imaginado. Premiada con un Tiger Award en el festival de Rótterdam de 2015, La obra del siglo figura ya como una de las obras más novedosas y sugerentes del cine cubano por su exploración de la estalgia. Carlos Quintela ha tenido la amabilidad de compartir con nosotros su cuaderno de trabajo, que compila fotos de localizaciones y fragmentos del story board. Este arsenal de imágenes se cierra con las obras que han formado parte de las tres exposiciones (La bota rusa, Carne rusa y Da Kantsa/ До конца) que desde 2011 ha reunido en Cienfuegos a artistas cubanos bajo la evocación de lo ruso-soviético. Forman parte de esa galería pintores, ilustradores y escultores como Alaín Martínez, Camilo Villalvilla, Rolando Quintero, Juan Carlos Echevarria y Jorge Luis Sanfiel y Luis A. P. Copperini.

Las formas de la estalgia es, como se puede ver, un gran proyecto colectivo que reúne a académicos, investigadores, artistas, cineastas y escritores. Me gustaría mostrar mi agradecimiento a todos ellos por la calidad de sus aportaciones y por su generosidad a la hora de compartirlas a través de esta publicación. Ha sido un verdadero lujo trabajar con ellos. Quiero manifestar, también, un especial reconocimiento hacia Jaume Peris, director de Kamchatka, que entendió el proyecto desde el primer día y le insufló una ambición que no estaba en el plan inicial. Él ha hecho posible que tanto Las formas de la estalgia como Mi abuelo murió leyendo a Pushkin puedan presentarse al lector con la mayor libertad y el máximo nivel de exigencia. El agradecimiento debe hacerse extensivo a todo el equipo editorial, de redacción, corrección y edición de la publicación, personificado particularmente en Karolina Zygmunt. 
No ya el proyecto, sino la mera posibilidad de su existencia, surgió una mañana de agosto de 2014 en Saint Jean Pied de Port/ Donibane Garazi, capital de la Baja Navarra que marca la entrada del Camino de Santiago a los Pirineos. No estábamos allí para recorrer el camino, pero desde ese promontorio orientado hacia el fin del mundo en el Occidente, Sonia García López, Raúl Pedraz y yo mismo hablamos largo y tendido de los senderos que llevan al otro extremo, al Lejano Este, a Rusia....a la mítica Kamchatka, la Kamchatka de Siberia: Камчатка. De ahí surgió la hipótesis de proponer esta publicación precisamente a esta otra Kamchatka, fascinante aventura académica y editorial de la Universitat de València. Para estos dos amigos, Sonia y Raúl, va mi último agradecimiento, precisamente porque ellos fueron los primeros en imaginar el camino a Kamchatka. 


\section{Bibliografía citada}

Boym, Svetlana (2001). The Future of Nostalgia. Basic Books: New York.

Kundera, Milan (2000). La ignorancia. Tusquets: Barcelona.

Loss, Jacqueline y Prieto, José Manuel (ed.) (2012). Caviar with Rum. Cuba-USSR and the Post-Soviet Experience. Palgrave Macmillan: New York.

Loss, Jacqueline (2013). Dreaming in Russian. The Cuban Soviet Imaginary. University of Texas Press: Austin.

Puñales-Alpízar, Damaris (2012). Escrito en cirílico. El ideal soviético en la cultura cubana posnoventa. Editoria Cuarto Propio: Santiago de Chile. 